\title{
Development of Non-Invasive Cardiology in Nepal
}

\author{
Dipanker Prajapati
}

Cardiovascular diseases (CVD) are the leading cause of death worldwide and developing countries are seeing an alarming increase in the rates of CVD. Non-Invasive Cardiology, a branch of cardiology, includes non-invasive testing for outpatient and admitted patients, utilizing tests to diagnose and treat cardiac diseases.

The development of non-invasive cardiology, or cardiology to be precise, started with establishment of department of medicine in Bir hospital in the year 1961. Department of cardiology was developed in the late 1970 s. ${ }^{1}$ The first Coronary Care Unit/ Intensive Care Unit (CCU/ICU), and one of the few in the South Asian region at that time, was started in Bir Hospital in the year 1974. NCD001 (Non Communicable Disease Code) for prevention and training in non-communicable disease was included in W.H.O regular budget to Nepal in the year $1985 .{ }^{1}$ Dr. Edgar Miller at Shanta Bhawan Hospital in Patan first introduced Electrocardiogram (ECG) service in Nepal in $1956 .^{2}$ In Bir Hospital, bicycle stress ECG service using treadmill was started in 1984 and in the year 1985, Echocardiography and Holter ambulatory ECG monitoring system were started. ${ }^{1,2}$ Similarly, the treadmill stress ECG was computerized in Bir Hospital for the first time in the year 1988., ${ }^{1,2}$ According to Dr. Mrigendra Raj Pandey, who was Head of Department of Medicine at that time, initiating Cardiology department with these facilities was quite challenging and needed lots of persuasion and help from government. Earlier, majority of the patients who could afford used to go to India for treatment, and with the start of these facilities in our country, the awareness of cardiac disease among general population gradually increased. During the initial phases, 50-70 patients visited out patient department (OPD) everyday. Important research works were also published in prestigious national as well as foreign journals at that period. ${ }^{3}$

According to Dr. D.B. Karki, who was also working in the department during same time, states that political will, public participation, medical professional's dedication and technical and financial support from different government and international agencies played an essential role in the development of Cardiac care in Nepal. Dr. Abanibhusan Upadhyaya, one of the team members of Cardiology in Bir hospital during its establishment, mentioned that initiating cardiology facilities in Nepal where there was no concept of heart disease among people was quite challenging. There were lots of help from the government as a plan of expansion of Bir Hospital. Initially there were few patients and there was virtually nothing happening outside Kathmandu valley. He stressed on need of more academic institutions for generation of trained manpower and decentralization of cardiology facilities to different parts of our nation.

With the establishment of Institute of Medicine (IOM) in 1972 and completion of Tribhuwan University Teaching Hospital (TUTH) in 1984, the facility of cardiology was extended in Nepal. Cardiac services provided in TUTH after its establishment played crucial role to further development of non-invasive cardiology. Norvic International Hospital, established in year 1994, was one of the first private hospitals to provide non-invasive cardiac facilities that are now provided by significant numbers of private hospitals in Kathmandu. Outside the Kathmandu valley, there were few hospitals like Manipal Teaching Hospital (established in the year 1994), B.P Koirala Institute of Health Sciences (established in the year 1993) and regional hospitals that were providing the non-invasive cardiac services to people. With the establishment of Shahid Ganaglal National Heart Centre (SGNHC) in 1995, the tertiary Centre for cardiovascular disease in Nepal, there was significantincrease in the quantity as well as quality of non-invasive tests. These tests are performed in thousands of numbers per year and the numbers are increasing every year. ${ }^{4}$ Non-invasive cardiology was further expanded with the establishment of Manmohan Cardiothoracic Vascular and Transplant Center in the year 2009. In the last decade the service of clinical cardiology and noninvasive cardiology are being provided by numerous hospitals and cardiac centers in Nepal.

ECG, introduced more than 50 years ago in our country, is the most common technique for the study of heart diseases. Apart from evaluation of various cardiac symptoms, ECG is considered to be gold standard forthe diagnosis of cardiac arrhythmias, conduction disturbances, pre-excitation syndromes, channelopathies and some aspects of acute ischemic heart diseases. The number of ECGs performed in our country has increased significantly compared to 1980s when few thousands ECGs were done every year. ${ }^{1,2}$ However, many remote areas of Nepal still lack this diagnostic tool, which is considered to be cheap and most common. There have been few studies that were conducted in Nepal regarding its correlation with different cardiac and noncardiac diseases. ${ }^{3,5,6,7}$ ECG exercise testing, started in year 1984, ${ }^{1,2}$ is performed to evaluate the cardiovascular system's response to exercise under carefully controlled conditions. It is used to assess patients with suspected or proven cardiovascular disease and to estimate prognosis and determine functional capacity, the likelihood and extent of coronary artery disease (CAD), and the effects of therapy. ${ }^{8}$ During its initial years of establishment, few hundreds tests were performed in Bir hospital. ${ }^{1,2}$ Today, around 10,000 tests are performed annually in SGNHC alone. ${ }^{9}$

Transthoracic Echocardiography (TTE) remains the most frequently used and usually the initial imaging test to evaluate all cardiovascular diseases related to structural, functional, or hemodynamic abnormality of the heart or great vessels. It is widely available, easy to use, and cost effective. This test, used primarily to diagnose, also can be used for screening and comparison of treatment in various cardiovascular diseases. ${ }^{10-23}$ Trans esophageal Echocardiography (TEE), a low risk procedure with complication rate of less than $0.1 \%$, is now considered essential in the evaluation of mitral valve, the left atrium or its appendage, an intracardiac mass, an atrial septal defect, endocarditis and its complication, and thoracic aortic lesions such as aortic dissection. The numbers of TEE, along with intraoperative TEE, performed are increasing every year and the diagnosis of these diseases has been made easier., ${ }^{9,24-27}$ Stress echocardiography, performed with exercise or the administration of a pharmacologic agent, is an excellent method for comparing wall motion, myocardial perfusion, pressure gradient, pulmonary pressure, valvular regurgitation, or filling pressures before and after a stress to identify pathologic conditions that are not 
apparent at rest. ${ }^{28}$ These tests are performed in major hospitals and health centers in Nepal in significant numbers. ${ }^{9}$ Since the establishment in year 1985, Echocardiographic studies have been significantly performed over the years ${ }^{9,29}$ and there have been multiple researches evaluating its efficacy, complications and study of prevalence of cardiac diseases as well as normal parameters among Nepalese population. ${ }^{10-23,30-32}$

The chest radiograph remains the most common $\mathrm{x}$-ray examination and one of the most difficult examinations to interpret. ${ }^{32}$ With the advent of technologies and development during the past decade, CT and MRI now enables rapid and accurate imaging of the cardiovascular system, including coronary arteries, coronary arterial wall, cardiac valves, myocardium and associated structures. According to Dr. Bhuwan Kayastha, consultant radiologist, since the establishment of Cardiac CT in the year 2008 in Nepal, 15-20 cardiac CTs are performed every month and apart form the CAD; the diagnosis of Aortic aneurysm, aortic dissection and pulmonary embolism has been much easier. Dr Ram Kumar Ghimire, consultant radiologist, states that the cardiac MRI was introduced in Nepal this year and is in its beginning phase and hopes it would slowly grow its momentum. Nuclear cardiology plays an important role in diagnosis and risk assessment of patients with suspected or known CAD. Due to its cost and availability, though introduced in year 2006, these tests are not performed routinely, however the use of these modalities has been increasing in the field of cardiovascular medicine. Ultrasound imaging of carotid artery wall thickness provides prognostic information on acute coronary event risk incremental to traditional risk factors. These data not only serves as diagnostic modality but also are helpful in predicting acute coronary events. ${ }^{33}$

Holter, tilt table test and ABP monitoring, introduced in the year 1980s, has been used in considerable amount every year ${ }^{9}$ and are used to evaluate various symptoms and diagnosis and treatment of hypertension and arrhythmias. Enhanced External Counterpulsation (EECP) was introduced in our nation in the year 2010 in SGNHC and has shown promising results among patients with refractory angina. ${ }^{34-36}$ There are some promising results in preventing CAD too. Fetal echocardiography, which was introduced in SGNHC in the year 2007, plays an important role in diagnosis of congenital heart disease and early intervention in its treatment modality. Currently, hundreds of fetal echocardiography are performed each year. ${ }^{9}$

Non-invasive tests not only are used to diagnose and treat patients but were also used to compare the prevalence of diseases and the outcome after treatment. These tests have been helpful for providing various data to implement different national treatment strategies in recent years. With the increasing number of hospitals and cardiac centers providing these tests and increasing number of manpower, population of rural areas of our nation is enjoying these facilities too. However, majority of population are still lacking the basic health facilities in our country. The needs for these facilities to reach these populations are increasing with increase in prevalence of cardiovascular disease in different parts of our country. According to Dr. Deewakar Sharma, coordinator of non-invasive cardiology at SGNHC, though there has been significant rise in the quantity of the non-invasive services in Nepal, the quality of these services needs to be developed to keep in pace with the advancement of non-invasive cardiology in modern world. He stresses the need of more dedicated manpower in non-invasive field as it has been overshadowed by interventional cardiology and the need for more research in the field of non-invasive cardiology, as it is not adequate.

Since the introduction of cardiology services in Nepal in the year 1970s in Bir Hospital, there have been numerous developments in the non-invasive services of Nepal. But these services are mainly available in major cities of our country, with large population still devoid of these facilities. Even the most common tests like ECG and Chest radiograph are not readily available in most part of our country. Like any developing country, poverty, high maternal and infant deaths, malnutrition and various communicable and non-communicable diseases challenge Nepal. Due to lack of policies and programs, most of the resources and technologies are being disproportionately utilized in certain parts of Nepal. The need of development of skill, manpower and technologies and its proper utilization plays an important role in development of cardiovascular medicine and the improvement of health system in Nepal.

It was felt that depending on research and scientific papers were inadequate for this article writing, as most of the development of non-invasive cardiology services was not documented. Therefore few of the cardiologists who were mainly devoted in non-invasive cardiology in Nepal were interviewed. However, the author and the editorial team would like to thank and honor all the physicians and cardiologists of Nepal through this article as each and everyone has played crucial role in the development of non-invasive cardiology in Nepal.

\section{References:}

1. Pandey MR. Cardiology services in Nepal. Souvenir, Bir Hospital Centenary; 1989-90: 63-64.

2. Karki D.B. Development of Cardiology in Nepal. Souvenir, Bir Hospital Centenary; 1989-90: 105-106.

3. Pandey, M.R. Evaluation of the role of clinical radiological and electro-cardiographical methods in the diagnosis of left ventricular hypertrophy.Ind. Heart Jour 1957; 9(3):165-179.

4. ShahidGangalal National Heart Centre, Annual Report. Various Years.

5. Nepal M, Upadhayaya AB, Tibrewal LP, et al. Study of normal ECGs of healthy Nepalese medical personals without any apparent medical illness. Nepalese Heart Journal 2003; 2(2): 45-51

6. Karki DB, Lohani S. Electrocardiographic intervals, Durations and axis of healthy Nepalese doctors with normal electrocardiogram. JNMA 1998:37: 413-421.

7. Humagain S, Keshari S, Gurung $\mathrm{R}$ et al. Electrocardiographic changes in Chronic Obstructive Pulmonary Disease patients with elevated pulmonary artery systolic pressure. Nepalese Heart Journal 2011;8(1):12-15.

8. Bajracharya $M$. Frequency of exercise induced myocardial ischemia in asymptomatic Diabetic patients. Nepalese Heart Journal 2008; 5(1): 11-12

9. Non-invasive cardiology and OPD services. ShahidGangalal National Heart Centre, Annual Report 2014:14-17

10. Gautam MP, Gautam S, Ghimire U, et al. Assessment of left ventricular mass regression in patients treated with various antihypertensive drugs. Nepalese Heart Journal 2011;8(1):48.

11. Humagain S, Twayana R, Koju R. Echocardiographic profile of patients in Dhulikhel Hospital, A medical college of Nepal. Nepalese Heart Journal 2014; 11(1): 13-17.

12. Karki P, Pandey I, Bhandary S, et al.An Echocardiographic evaluation of diastolic dysfunction in patients with subclinical hypothyroidism and the effect of L-thyroxine treatment: A hospital based study. Nepalese Heart 
Journal 2014; 11(1): 33-38.

13. KC MB, Sharma D, Shresth MP, et al, Prevalence of rheumatic and congenital heart disease in school children of Kathmandu valley in Nepal, Indian Heart Journal 2003;55(6):615-8.

14. Sharma D, KC MB, Rajbhandari S, et al, Echocardiographic profile of congenital heart diasease at ShahidGangalal National Heart Centre, NEPAS Journal, 2005; 25:11-14.

15. Rayamajhi A, Sharma D, Shakya U. Clinical, laboratory and echocardiography profile of acute rheumatic fever in Nepali Children. Ann Trop Pediatr 2007;27(3): 169-177.

16. Shah R. K, Upadhyaya A.B, Tibrewala L.P, et al. Pattern and prevalence of Rheumatic heart disease by echocardiographic evaluation. Nepalese Heart Journal 2003; 2(2): 8-13

17. Shrestha UK, Bhattarai TN, Pandey MR. Prevalence of rheumatic fever and rheumatic heart disease in school children in rural community of the hill region of Nepal. Indian Heart J 1991:43:39-41.

18. Regmi PR, Pandey MR. Prevalence of rheumatic fever and rheumatic heart disease in school children of Kathmandu city. Indian Hear J 1997; 49:518-520.

19. Limbu Y R, Maskey A. Current status of Rheumatic Fever and Rheumatic Heart Disease in Nepal. Journal of Nepal Medical Association 2002; 41: 514-517.

20. Koju R, Gurung R, Pant P, et al. Pattern of Heart valve involvement in Rheumatic Heart Disease. Nepalese Heart Journal 2009;6(1):17-22.

21. HumagainS,Gurung R, Pant P, et al, Pattern of Valvular involvement and demographic features of patients on injection Benzathine Penicillin at Dhulikhel Hospital, Kathmandu University. Nepalese Heart Journal 2012; 9(1): 16-19.

22. Shrestha NR, Kalesan B, Karki P, et al. Rheumatic heart disease: pilot study for a population based evaluation of prevalence and cardiovascular outcomes among schoolchildren in Nepal. BMJ Open 2012; 2: 1-5.

23. Sharma D, Baidya SG, Prajapati D, et al.Congenital Absence of pericardium. Nepalese Heart Journal 2009;9(1): 53-55.

24. Shah RK. Initial experience of Transesophageal Echocardiography in NAMS Bir Hospital. Nepalese Heart Journal 2010; 7(1): 44-47

25. Maskey A, Sharma D, K.C MB, et al; Intraoperative Transesophageal Echocardiography in Nepal; Nepalese Heart Journal, 2003;2(2):42-44.

26. Sharma D, Maskey A, KC MB, et al, Comparison of transthoracic and transesophageal echocardiography for the detection of left atrial thrombus in rheumatic mitral valvular disease. Journal of Nepal Medical Association 2004; 43:182-184.

27. SimkhadaR, KC MB, Bhatt YD, et al. Trans- oesophageal Echocardiographic Appraisal of Left Atrial Appendage Clot in Severe Mitral Stenosis. Nepalese Heart Journal 2013;10(1):27-29.

28. Shah RK. Safety and diagnostic accuracy of Dobutamine Stress Echocardiography. Nepalese Heart Journal 2009;6(1):68-78.

29. Department of Cardiology at MCVTC. Manmohan Cardiothoracic Vascular and Transplant Center. Annual Report 2015;3-7.

30. Prajapati D, Sharma D, Baidya S.G, et al. Normal Echocardiographic Parameters of Healthy Adult Individuals working in National Heart Centre. Nepalese Heart Journal 2009;9(1): 3-6.

31. Prajapati D, Sharma D, Regmi PR, et al. Epidemiological survey of Rheumatic Fever, Rheumatic Heart Disease and Congenital Heart Disease among school children in Kathmandu valley of Nepal. Nepalese Heart Journal 2013;10(1): 1-5.

32. Adhikary KP, Jha S, Ghimire RK, et al. Comparison of plain X-ray finding of ventricular enlargement with echocardiography. Nepalese Heart Journal 2003; 2(2): 18-26.

33. LimbuYR, Rajbhandari R, Sharma R, etal. Carotidintimamedia thickness (CIMT) and carotid plaques in young Nepalese patients with angiographically documented coronary artery disease. CardiovascDiagnTher 2015; 5(1): $1-7$.

34. Adhikari CM, Prajapati D, Thapaliya S, et al.Efficacy of enhanced external counterpulsation: our experience. Cardiometry 2014;5:71-77

35. Adhikari CM, Prajapati D, Thapaliya S, et al. Outcome of enhanced external counterpulsation in different groups of refractory angina patients. Comprehensive Research Journal of Biological Science (CRJBS) 2013;1(1):32-35.

36. Adhikari CM, Prajapati D, Thapa S, et al.Efficacy of Enhanced External Counterpulsation (EECP) in Nepalese chronic stable Angina patient: a single centre prospective study at ShahidGangalal National Heart Center (SGNHC).Nepalese Heart Journal 2009;9(1):2024.
Cite this article as: Dipanker Prajapati. Development of Non-Invasive Cardiology in Nepal. Nepalese Heart Journal 2015;12(2):61-63. 